\title{
Causes of Nephrectomy in Shiraz City in 2018
}

\author{
Rasol Zare Moayedi ${ }^{1}$, Mohsen Khalili2*
}

1. MD, Faculty of Medicine, Aja University of Medical Sciences, Tehran, Iran

2. PhD Student, Faculty of Medicine, Kerman University of Medical Sciences, Kerman, Iran

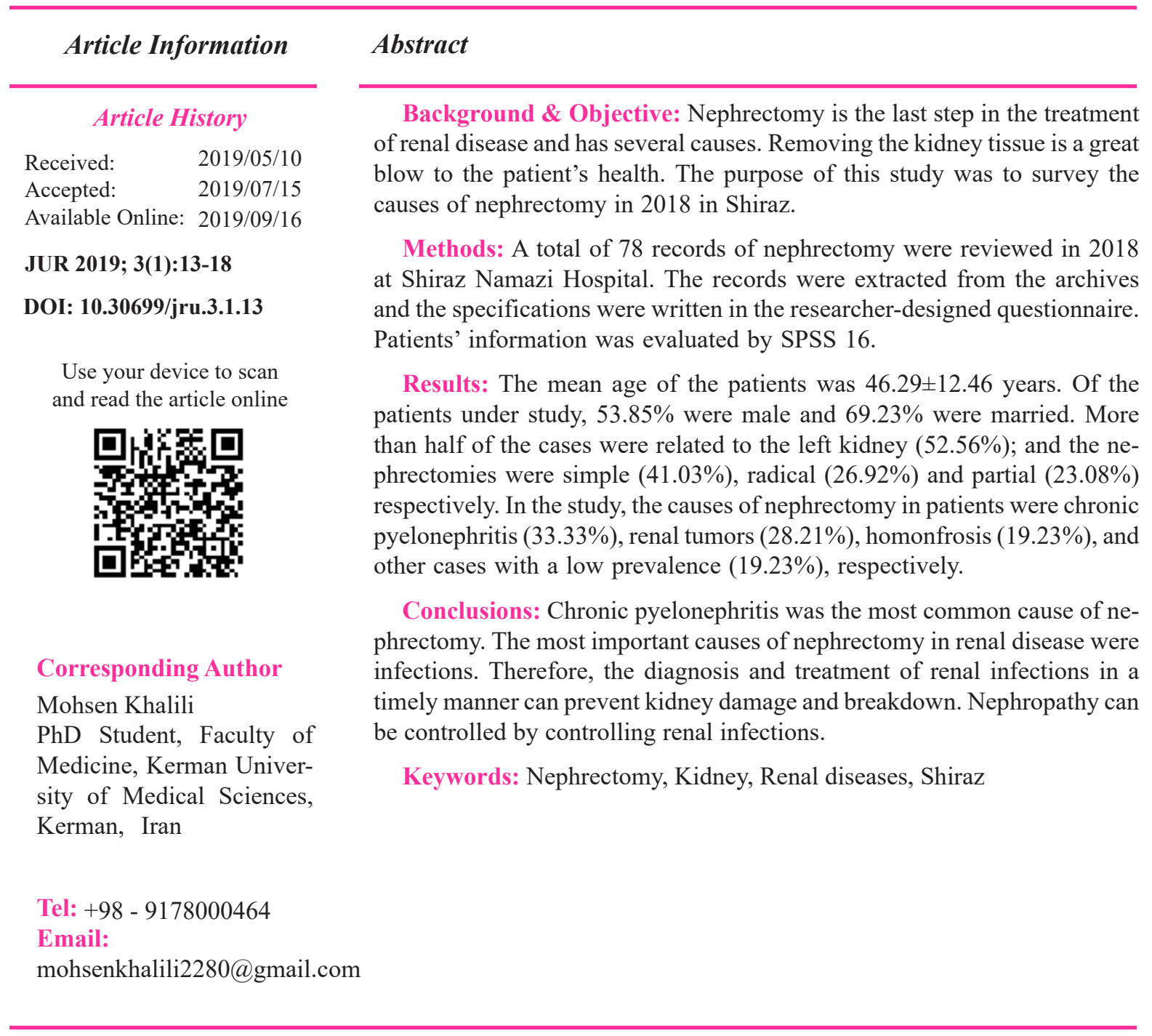

How to cite this article:

Zare Moayedi R, Khalili M. Causes of Nephrectomy in Shiraz City in 2018. J Res Urol. 2019; 3 (1): 13-18 
علا نفركتومى در شهر شيراز در سال IrqV

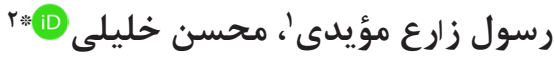

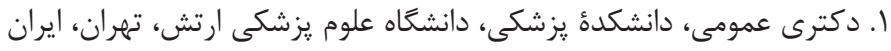

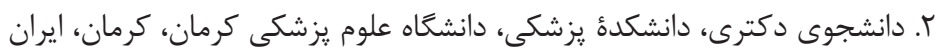

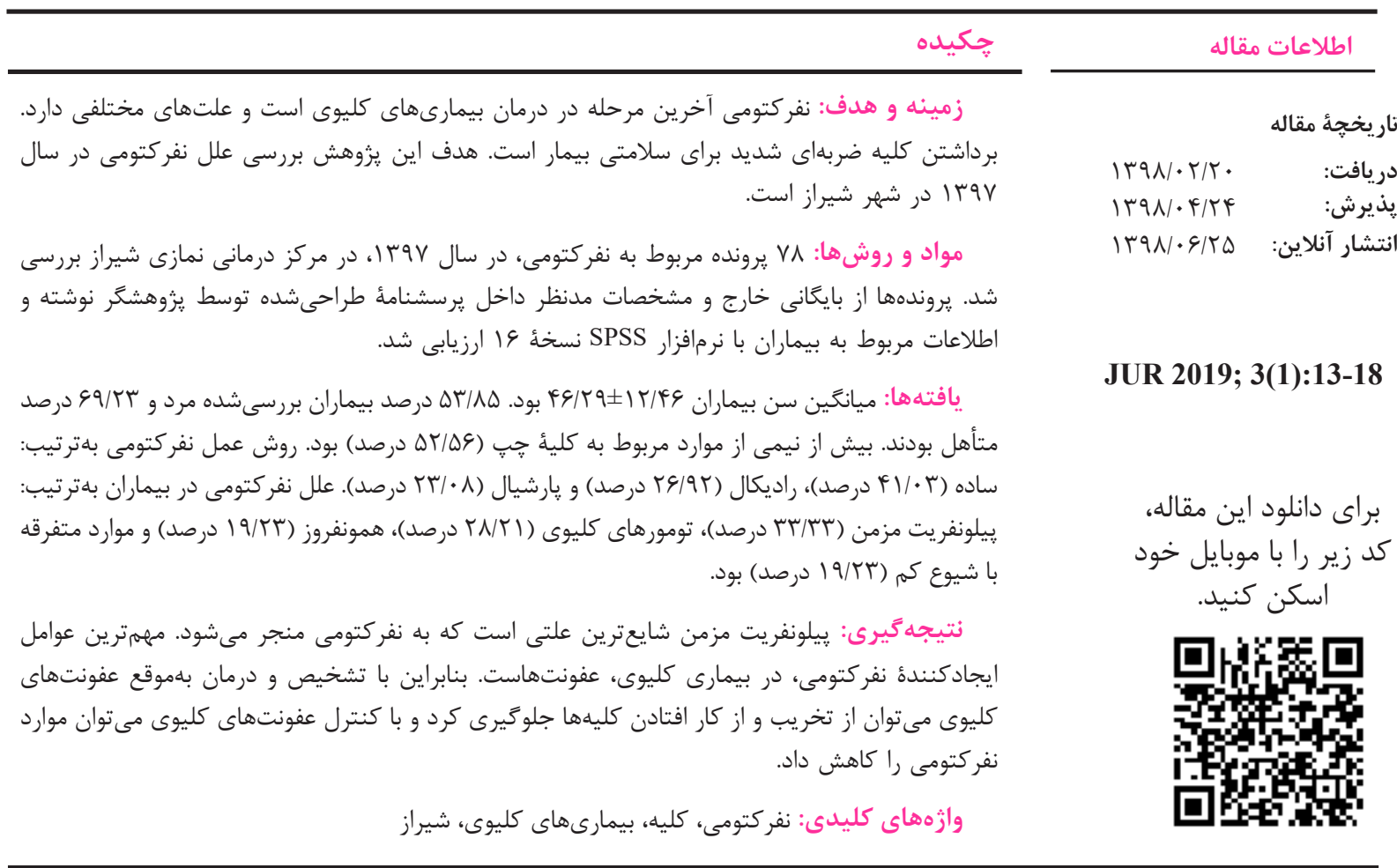

نويسندة مسئول: محسن خليلى، دانشجوى دكترى، دانشكدة يزشكى، دانشگاه علوم يزشكى كرمان، كرمان، ايران

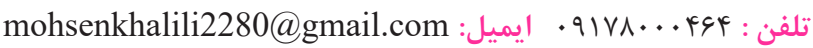




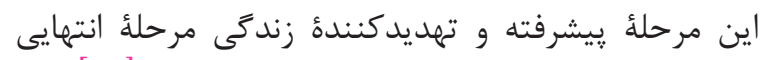

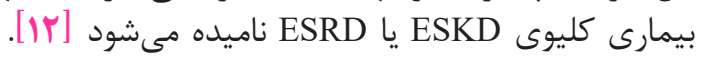
بررسى هاى جند سال كَذشته در جهان و ايران نشان

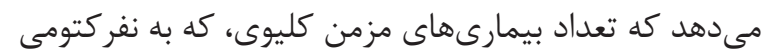

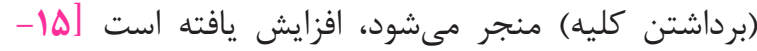

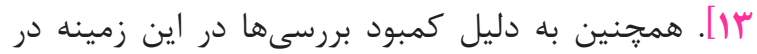

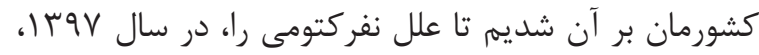

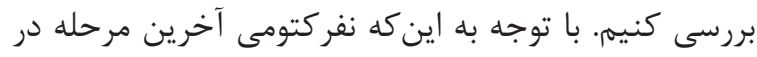

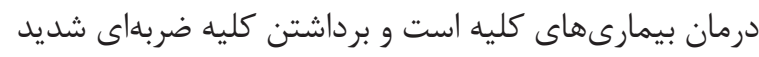

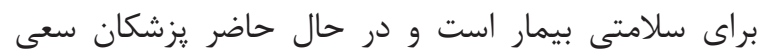

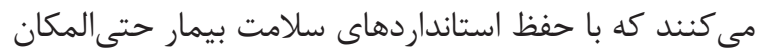

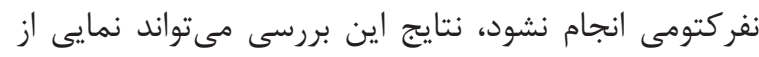

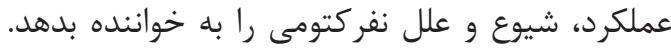

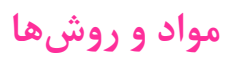

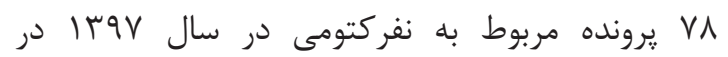

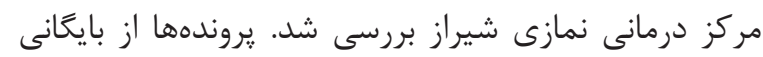

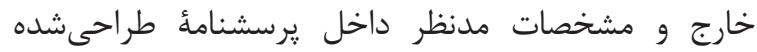

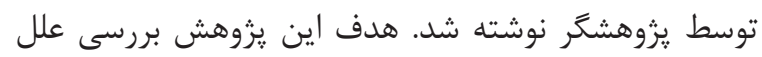

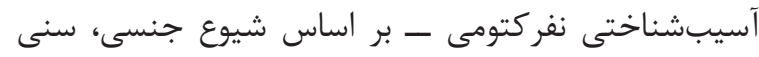

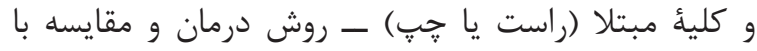

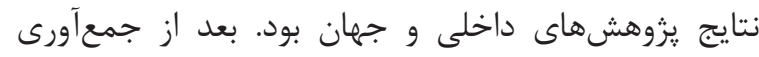

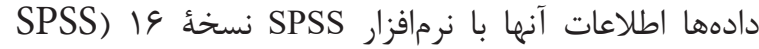
(Inc.,Chicago, IL. USA

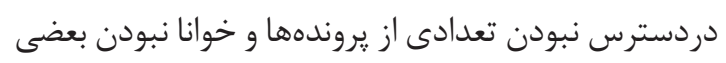

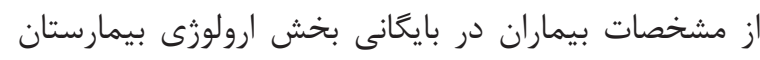

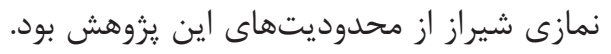

يافته ها

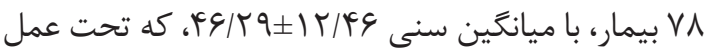

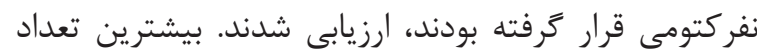

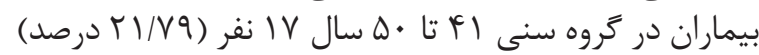

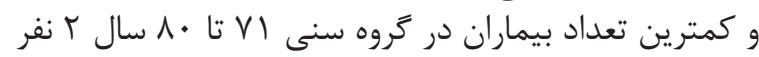

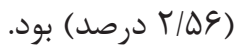

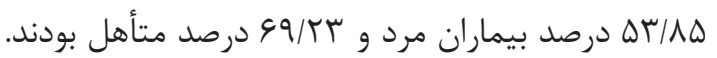

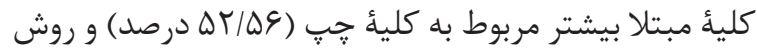

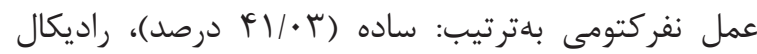

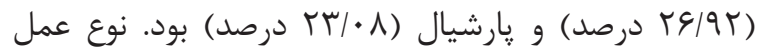

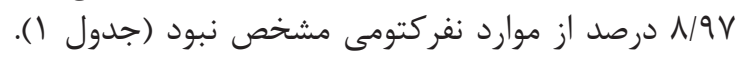

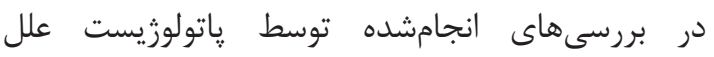

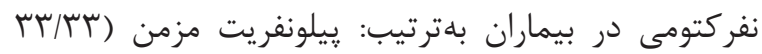

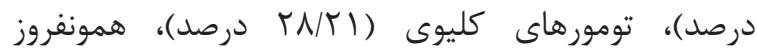

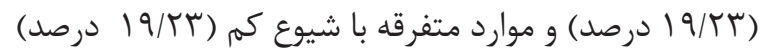

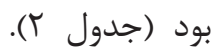

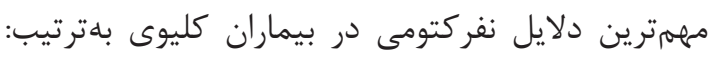

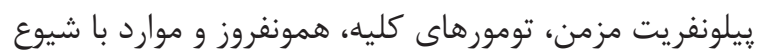

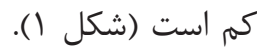

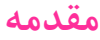

كليهها اركانهايى شَفتانكَيز هستند كه با دفع ضايعات

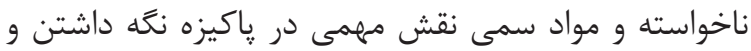

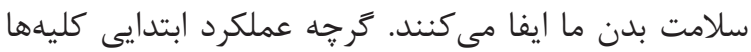

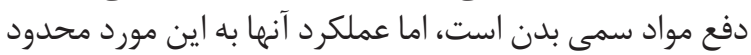

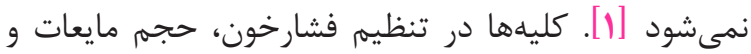

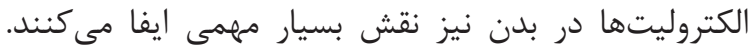

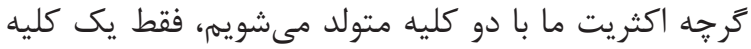

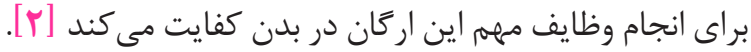

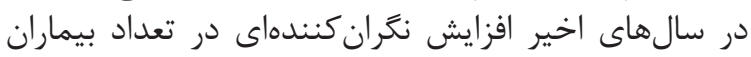

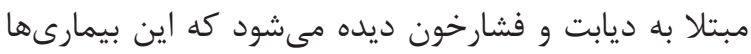

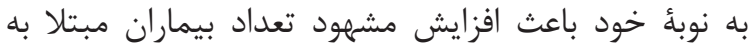

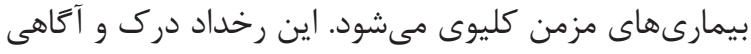

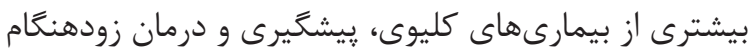

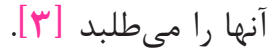

كليهها از حياتىترين اركانهاى بدن اندان انسان هستند.

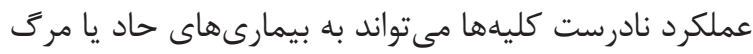

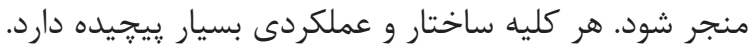

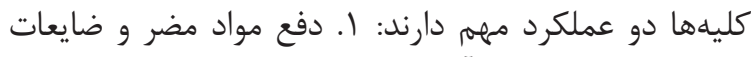

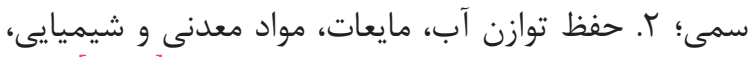

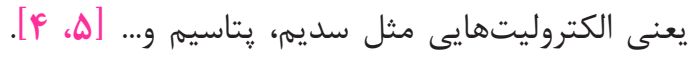

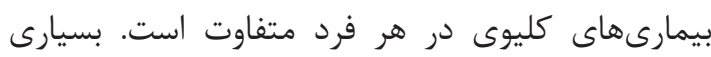

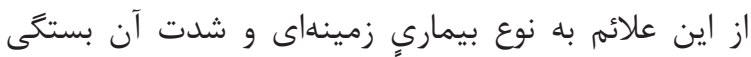

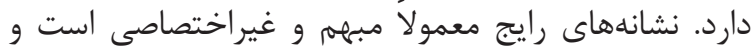

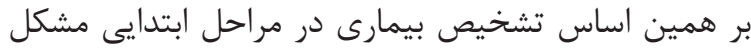

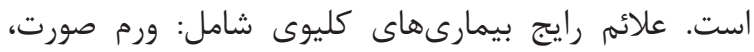

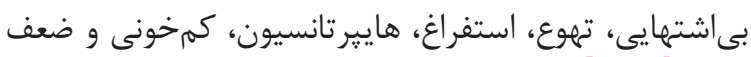

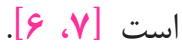

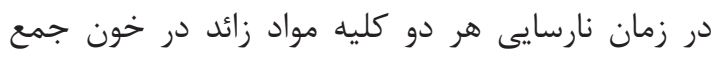

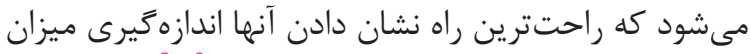

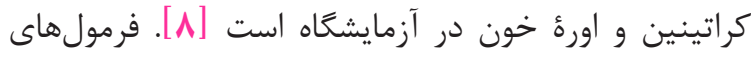

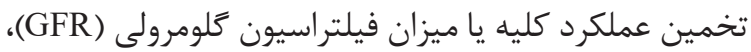

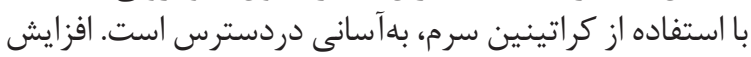

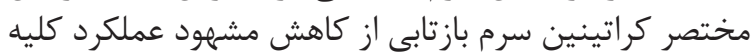

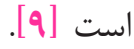

نارسايى كليوى مى تواند ماهيت حاد يا مزمن داشته باد باشد باش.

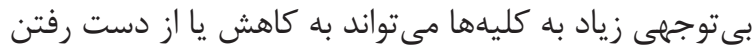

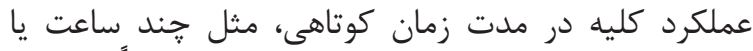

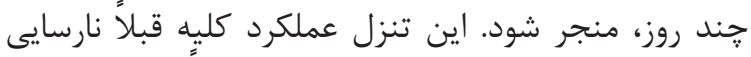

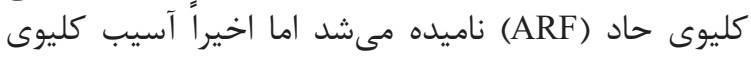

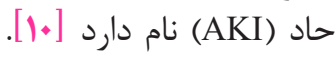
از دست رفتن تدريجى، پِيشرونده و بركشتنانيذير عملكرد

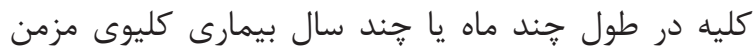
نام دارد كه ييش از اين نارسايى كليوى مزمن (CRF) (CKD)

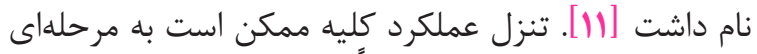

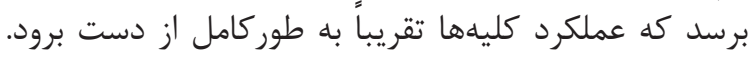


جدول ا. علل بر رسى نفر كتومى بر اساس مشخصات دموكرافيك بيماران

\begin{tabular}{|c|c|c|c|}
\hline درصد & تعداد & متغيير & مشخصات دموكرافيك \\
\hline$\Delta \Gamma / \Lambda \Delta$ & et & 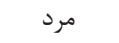 & \multirow{2}{*}{ جنسيت } \\
\hline$\forall \& / 10$ & re & زن & \\
\hline$r \cdot / V V$ & TF & مجرد & \multirow{2}{*}{ وضعيت تأهل } \\
\hline $99 / \pi$ & $\Delta F$ & متأهل & \\
\hline FV/FF & $r v$ & راست & \multirow{2}{*}{ كليئ مبتلا } \\
\hline$\Delta T / \Delta S$ & il & דֶֶ & \\
\hline$r \pi / \cdot \Lambda$ & 11 & يارشيال & \multirow{4}{*}{ روش نفركتومى } \\
\hline $\mid q 1 / . r$ & rt & 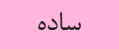 & \\
\hline re/9T & rI & راديكال & \\
\hline N/9V & v & تعييننشده & \\
\hline
\end{tabular}

\begin{tabular}{|c|c|c|}
\hline درصد & تعداد & علل نفركتومى \\
\hline זr/זr & rq & ييلونفريت مزمن \\
\hline TN/TI & tr & تومورهاى كليه \\
\hline \multirow[t]{2}{*}{ 19/r } & 10 & همونفروز \\
\hline & & (موارد متفرقه) \\
\hline$g|f|$ & $\Delta$ & بيلونفريت حاد \\
\hline Q/IT & f & آبسأ كليوى \\
\hline$r / \Delta G$ & r & رد بِيوند مزمن \\
\hline$r / \Delta Q$ & r & رد ييوند حاد \\
\hline $1 / T \Lambda$ & 1 & ساب كيسولار \\
\hline $1 / \Gamma \Lambda$ & 1 & كيست هيداتيك \\
\hline
\end{tabular}

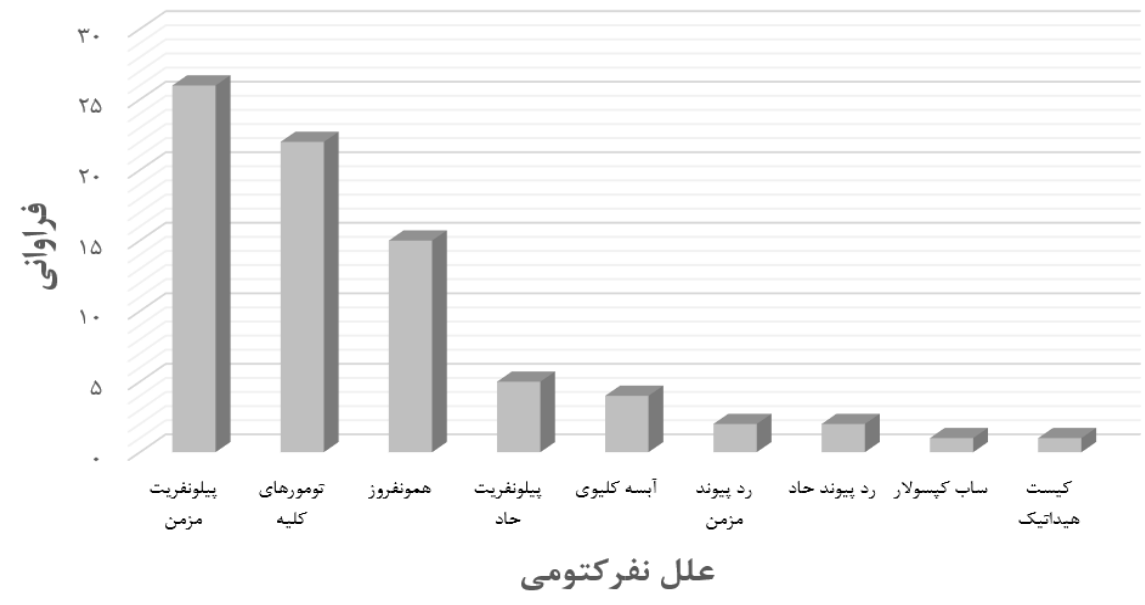

شكل 1. نمودار فراوانى علل نفركتومى در بيماران كليوى 


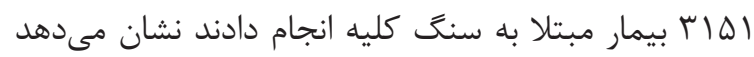

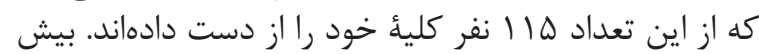

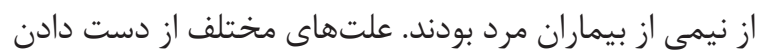

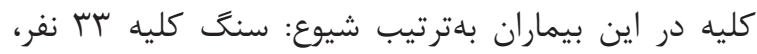

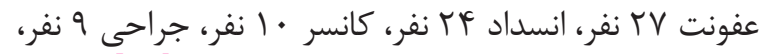

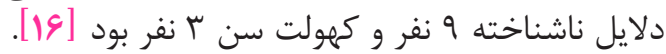

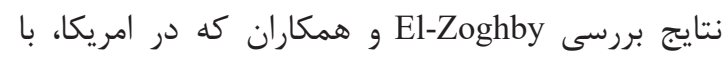

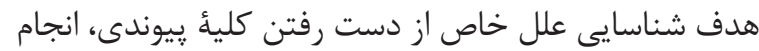

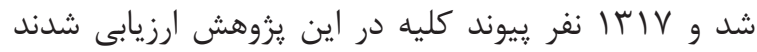

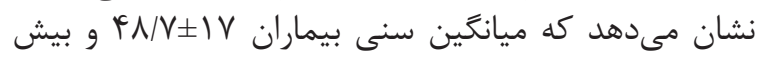

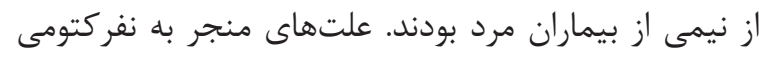

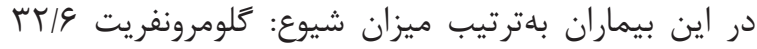

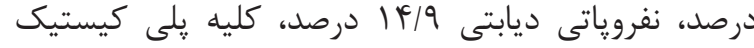

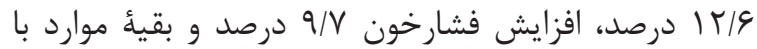

$$
\text { شيوع كم بود [IV] }
$$

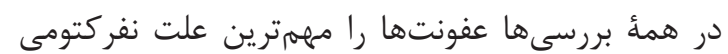

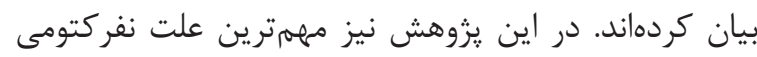

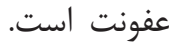

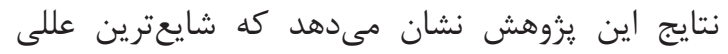

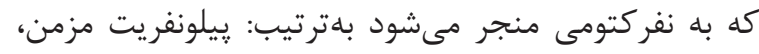

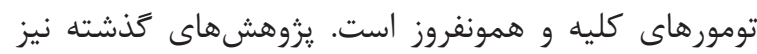

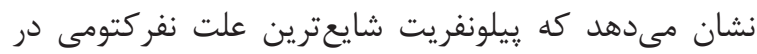

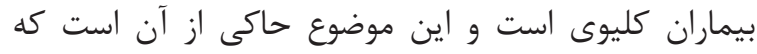

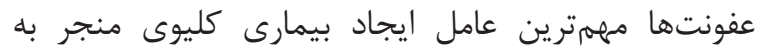

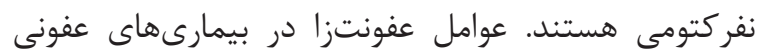

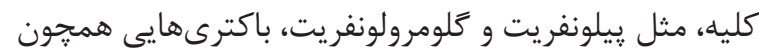

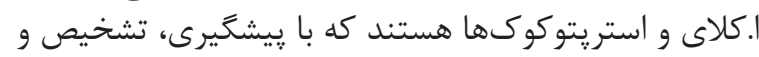

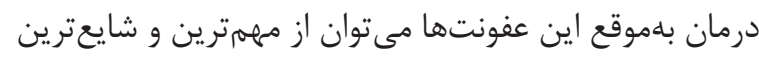

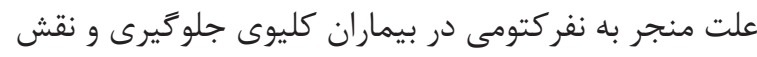
مهمى در سالم ماندن كليه در بيماران كليوى ايفا كرد.

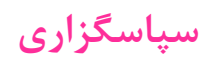

از بخش ارولوزى بيمارستان نمازى شيراز به دليل همكارى و مساعدت كمال تشكر را داريم.

$$
\text { تعارض در منافع }
$$

بين نويسندكان هيج كَونه تعارضى در منافع وجود ندارد.

$$
\text { بحث و نتيجه تيرى }
$$

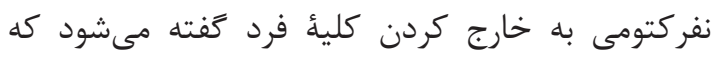

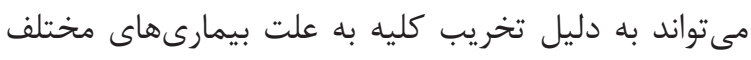

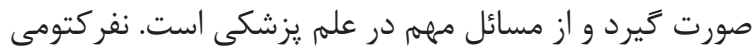

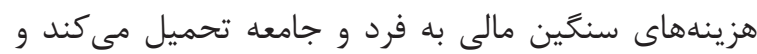

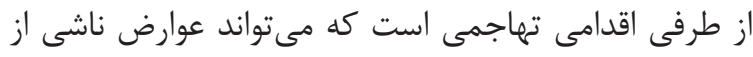

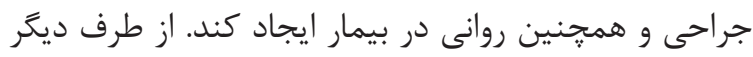

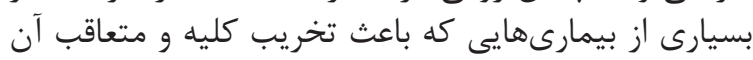

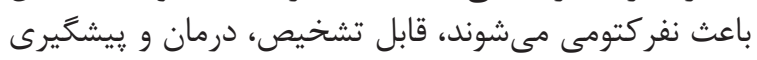

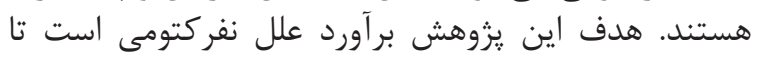

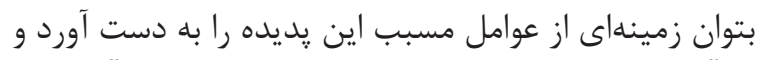

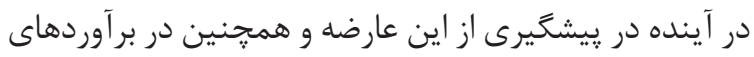
سلامت جامعه استفاده كرد.

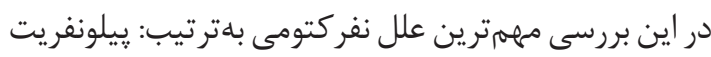

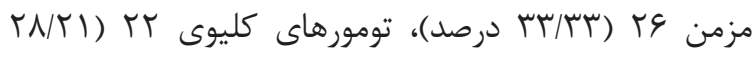

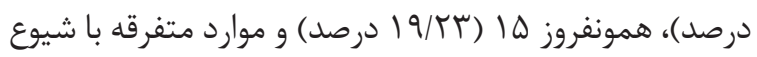

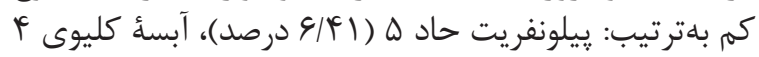

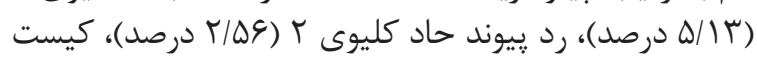

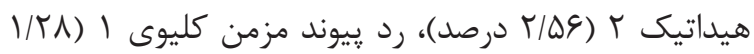

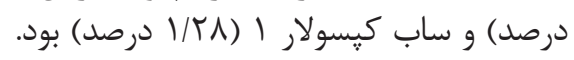

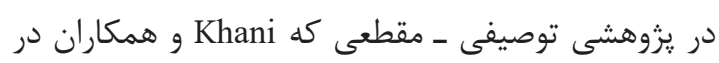

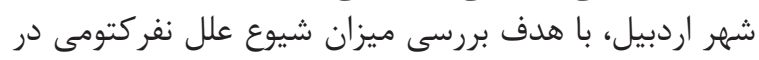

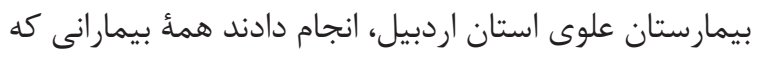

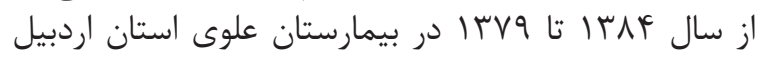

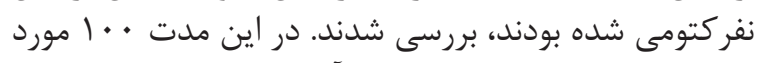

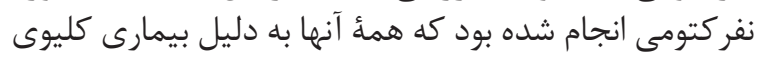

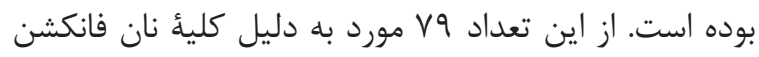

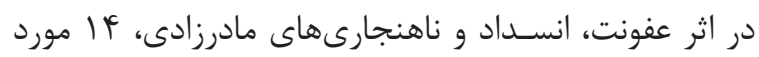

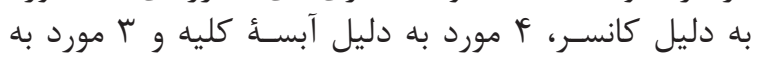

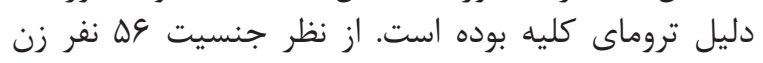

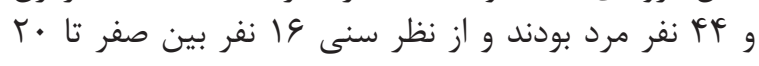

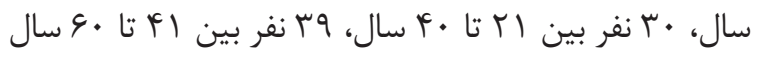

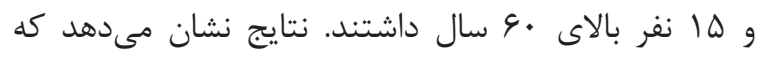

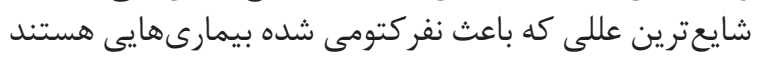

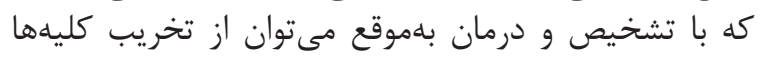

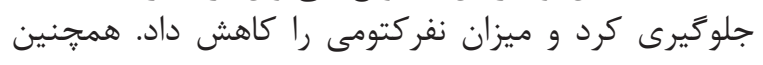

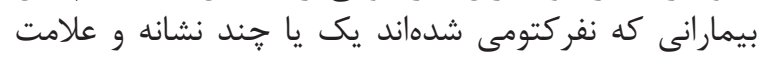

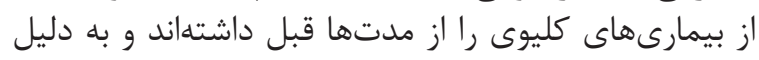

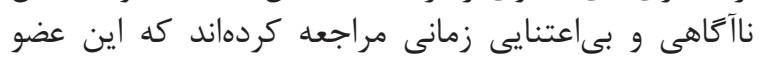

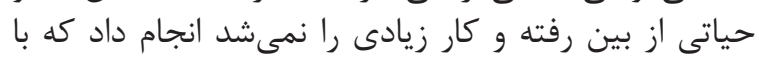

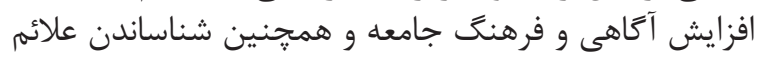

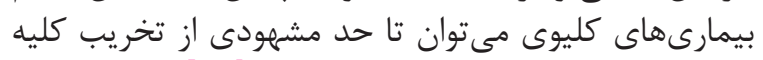

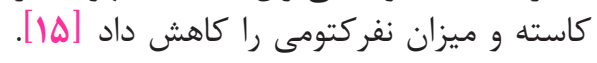

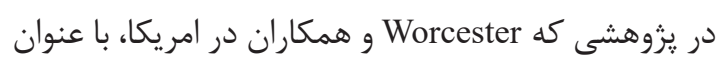
علل و عوارض از دست دادن كليه در بيماران سنَ كليه، بر أر ان 


\section{References}

1. Motzer RJ, Jonasch E, Agarwal N, Beard C, Bhayani S, Bolger GB, Chang SS, Choueiri TK, Costello BA, Derweesh IH, Gupta S. Kidney cancer, version 3.2015. Journal of the National Comprehensive Cancer Network. 2015 Feb 1;13(2):151-9.

2. Gilbert S, Weiner DE. National Kidney Foundation Primer on Kidney Diseases E-Book. Elsevier Health Sciences; 2017 Sep 11. 224-56.

3. Webster AC, Nagler EV, Morton RL, Masson P. Chronic kidney disease. The lancet. 2017 Mar 25;389(10075):1238-52.

4. Hill NR, Fatoba ST, Oke JL, Hirst JA, O'Callaghan CA, Lasserson DS, Hobbs FR. Global prevalence of chronic kidney disease-a systematic review and meta-analysis. PloS one. 2016 Jul 6;11(7):e0158765.

5. Milongo D, Kamar N, Del Bello A, Guilbeau-Frugier C, Sallusto F, Esposito L, Dörr G, Blancher A, Congy-Jolivet N. Allelic and Epitopic Characterization of Intra-Kidney Allograft Anti-HLA Antibodies at Allograft Nephrectomy. American Journal of Transplantation. 2017 Feb;17(2):420-31.

6. Glassock RJ, Rule AD. Aging and the kidneys: anatomy, physiology and consequences for defining chronic kidney disease. Nephron. 2016;134(1):25-9.

7. Khan SR, Pearle MS, Robertson WG, Gambaro G, Canales BK, Doizi S, Traxer O, Tiselius HG. Kidney stones. Nature Reviews Disease Primers. 2016 Feb 25;2:16008.

8. Lasisi TJ, Raji YR, Salako BL. Salivary creatinine and urea analysis in patients with chronic kidney disease: a case control study. BMC nephrology. 2016 Dec;17(1):10.

9. Webster AC, Nagler EV, Morton RL, Masson P. Chronic kidney disease. The lancet. 2017 Mar 25;389(10075):1238-52.

10. Edelstein CL. Biomarkers in acute kidney injury. InBiomarkers of Kidney Disease 2017 Jan 1 (pp. 241-315). Academic Press.

11. Malhotra R, Craven T, Ambrosius WT, Killeen AA, Haley WE, Cheung AK, Chonchol M, Sarnak M, Parikh CR, Shlipak MG,
Ix JH. Effects of intensive blood pressure lowering on kidney tubule injury in CKD: a longitudinal subgroup analysis in SPRINT. American Journal of Kidney Diseases. 2019 Jan 1;73(1):21-30.

12. Harris DC, Davies SJ, Finkelstein FO, Jha V, Donner JA, Abraham G, Bello AK, Caskey FJ, Garcia GG, Harden P, Hemmelgarn B. Increasing access to integrated ESKD care as part of universal health coverage. Kidney international. 2019 Apr 1;95(4):S133.

13. Mazdak H, Ghavami M, Dolatkhah S, Daneshpajouhnejad P, Fesharakizadeh M, Fesharakizadeh S, Atapour A, Mahzouni P, Hashemi M, Salajegheh R, Taheri D. Pathological assessment of allograft nephrectomy: An Iranian experience. Journal of research in medical sciences: the official journal of Isfahan University of Medical Sciences. 2018;23.

14. Shariati E, Bakhtiari J, Khalaj A, Molazem M, Shariati E, Niasari-Naslaji A. Clinical and paraclinical evaluation of partial nephrectomy using laparoscopy and open surgery in dogs: new suturing technique. Iranian journal of veterinary research. 2017;18(1):1.

15. Khani H. The prevalence of nephrectomy causes in Alavi hospital in Ardabil province in 2000-2004. AUMS. 2009; 17 24.

16. Worcester E, Parks JH, Josephson MA, Thisted RA, Coe FL. Causes and consequences of kidney loss in patients with nephrolithiasis. Kidney international. 2003 Dec 1;64(6):2204-13.

17. El-Zoghby ZM, Stegall MD, Lager DJ, Kremers WK, Amer H, Gloor JM, Cosio FG. Identifying specific causes of kidney allograft loss. American Journal of Transplantation. 2009 Mar;9(3):527-35. 